This item was submitted to Loughborough's Research Repository by the author.

Items in Figshare are protected by copyright, with all rights reserved, unless otherwise indicated.

\title{
Accidental exposure to politics on social media as online participation equalizer in Germany, Italy, and the United Kingdom
}

PLEASE CITE THE PUBLISHED VERSION

https://doi.org/10.1177/1461444815616223

\section{PUBLISHER}

Sage (c) The Author(s)

\section{VERSION}

AM (Accepted Manuscript)

\section{PUBLISHER STATEMENT}

This work is made available according to the conditions of the Creative Commons Attribution-NonCommercialNoDerivatives 4.0 International (CC BY-NC-ND 4.0) licence. Full details of this licence are available at: https://creativecommons.org/licenses/by-nc-nd/4.0/

\section{LICENCE}

CC BY-NC-ND 4.0

\section{REPOSITORY RECORD}

Valeriani, Augusto, and Cristian Vaccari. 2015. "Accidental Exposure to Politics on Social Media as Online Participation Equalizer in Germany, Italy, and the United Kingdom”. Loughborough University. https://hdl.handle.net/2134/28254. 


\title{
Accidental exposure to politics on social media as online participation equalizer in Germany, Italy, and the United Kingdom
}

\section{Augusto Valeriani}

University of Bologna

\section{Cristian Vaccari}

Royal Holloway, University of London and University of Bologna

\begin{abstract}
We assess whether and how accidental exposure to political information on social media contributes to citizens' online political participation in comparative perspective. Based on three online surveys of samples representative of German, Italian, and British internet users in the aftermath of the 2014 European Parliament elections, we find that accidental exposure to political information on social media is positively and significantly correlated to online participation in all three countries, particularly so in Germany where overall levels of participation were lower. We also find that interest in politics moderates this relationship, so that the correlation is stronger among the less interested than among the highly interested. These findings suggest that inadvertent encounters with political content on social media are likely to reduce the gap in online engagement between citizens with high and low interest in politics, potentially broadening the range of voices that make themselves heard.
\end{abstract}




\section{Keywords}

Online political participation, accidental exposure, political information, internet and politics, social media, comparative research, Germany, Italy, United Kingdom

\section{Corresponding author}

Augusto Valeriani, University of Bologna, Via Giacomo della Torre, 5, 47100 Forlì, Italy. Email: augusto.valeriani@unibo.it

\section{Acknowledgements}

In accordance with Italian academic conventions, we specify that Augusto Valeriani wrote the sections titled "Introduction”, "Hypotesis and Research Questions", "Data, Variables, and Models" and "Discussion", and Cristian Vaccari wrote the sections titled "Literature Review", "Findings" and "Conclusions".

\section{Funding}

This work was supported by the Italian Ministry of Education "Future in Research 2012" initiative (project code RBFR12BKZH) for the project titled "Building Inclusive Societies and a Global Europe Online: Political Information and Participation on Social Media in Comparative Perspective" (http://www.webpoleu.net).

\section{Author biographies}


Augusto Valeriani is Assistant Professor in Media Sociology at the Department of Political and Social Sciences, University of Bologna (Italy). His research focuses on digital media and politics, both in national and international contexts. He is the author of several articles and three monographs. His latest book is Twitter Factor (Rome, 2011).

Cristian Vaccari is Reader in Politics at Royal Holloway, University of London and Associate Professor in Political Science at the University of Bologna. He studies political communication in comparative perspective with a particular focus on digital media, and is the Principal Investigator of a comparative research project on the relationship between social media and political engagement in Germany, Italy, and the United Kingdom from 2013 until 2016 (http://www.webpoleu.net/). His latest book is Digital Politics in Western Democracies: A Comparative Study (Johns Hopkins University Press, 2013). 


\section{Introduction}

In his book Information and American Democracy Bruce Bimber (2003) argued that, in the study of political phenomena, transformations in information technology are relevant because "information itself is relevant" (p. 8) for politics and democracy. As the Internet has enhanced choice opportunities in individualized media diets, it has become easier for citizens to select not only the information they want but also whether or not they want to be informed. Several authors (e.g. Bimber and Davis, 2003; Prior, 2007; Brundidge and Rice, 2009) have argued that these affordances of the internet make the information rich get richer, while leaving the politically uninterested or uninformed trapped in such condition. Others (e.g. Tewksbury et al., 2001), however, highlight that non-political websites mix a highly diverse spectrum of contents, suggesting that "The web may be unique in its ability to provide a typical user with an array of information choices that extend far beyond what he or she intentionally seeks" (Tewksbury et al., 2001: 534). Consequently, citizens surfing the internet, in spite of exercising more and broader choice than on the mass media, can also be accidentally exposed to news they were not looking for. This may in turn enhance political learning and participation, perhaps especially among those who, being less politically interested and involved, are more likely to stumble on political news online than to actually seek it.

Starting from these competing premises, scholars have debated the consequences of the internet for citizens' political information and participation 
and for inequalities in those patterns among different types of citizens. Whereas many (e.g. Scheufele and Nisbet, 2002; Norris, 2003; Xenos and Moy, 2007) supported the "rich get richer" theory, others (e.g. Boulianne, 2009), especially when emphasizing opportunities for accidental exposure (Tewksbury et al., 2001), tended to be more optimistic, at least in regard to the potential of the internet to increase citizens' knowledge of current and political affairs.

Social media may distinctively contribute to these patterns in ways not accounted for by previous theory and research. Andrew Chadwick (2009) highlights that web 2.0 platforms have lowered the threshold for producing, distributing and engaging with political information on the web. The resulting "information exuberance" (Chadwick, 2009) could increase the likelihood that citizens are accidentally exposed to news online (Gil de Zúñiga and Valenzuela, 2011), which in turn may affect patterns of political engagement. However, to date, few studies have focused on this relationship, and even fewer (e.g. Kim et al., 2013) have assessed the extent to which it is moderated by other individual or systemic variables.

To address these issues, we survey representative samples of British, German, and Italian internet users to test whether accidental exposure to political information on social networking websites predicts citizens' engagement in a broad spectrum of online political activities. We also test whether interest in politics moderates this relationship and compare these patterns across the three countries we have surveyed. We show that accidental exposure to political content 
on social media is positively correlated with political engagement online and that interest in politics moderates this relationship, so that the strength of the correlation between accidental exposure to political information on social media and online political participation decreases as interest in politics increases. This suggests that inadvertent exposure to political content on social media may result in a reduction in the online engagement gap between citizens with high and low interest in politics.

\section{Literature Review}

\subsection{Voluntary and inadvertent exposure to political information online}

The relationship between internet use and political participation has been widely discussed in social science research. Early debates were dominated by the argument that the selective nature of the web made it unsuitable to inform and mobilize uninterested citizens (Margolis and Resnick, 2000; Bimber and Davis, 2003; Norris, 2003). As Downs (1957) pointed out, whereas political information is costly to obtain and process, the perceived benefits of its consumption depend on individuals' motivations, especially their interest in politics. Even if the internet reduces information acquisition costs to almost zero (once access is available), processing costs and perceived benefits still depend on individual characteristics that the web per se cannot change. By contrast, the deluge of diverse content that can be found on the web offers users who are not interested in politics plenty of opportunities to avoid it. The resulting prediction was that, similarly as 
newspapers (Eveland and Scheufele, 2000), the internet would not reduce, but widen, the information and engagement gaps between the politically interested and the uninterested. Consistently, Prior (2007) demonstrated that greater media choice (i.e., cable television and internet access) widens gaps in political information and electoral participation between individuals who prefer news and those who prefer entertainment. Along these lines, Xenos and Moy (2007) found that the effects of political information acquired online on civic and political participation are contingent on political interest, with the highly interested experiencing greater participatory gains than the less interested.

Although these theoretical arguments and empirical findings are persuasive, they fail to address three important factors that could potentially lead to different conclusions. First, there are limits to the purposefulness of the internet as an informational tool, as some affordances of the web can lead individuals to accidentally encounter content that they did not actively seek; secondly, these limits change over time as a function of technological innovations and adoption thereof; thirdly, changes occurring in digital media and their social uses over the last few years suggest that opportunities for accidental exposure to various types of information-including political news and opinions-have increased rather than decreasing.

As Downs (1957) argued, individuals can purposefully acquire information as a result of a rational calculus whereby they weigh its costs and benefits-in which case we should expect the politically uninterested to opt out most of the 
time-but they can also gather political news or information as a by-product of other activities that they conduct in their everyday lives. This can take the form of direct experience suggesting cues about the state of the economy and the quality of public services, informal conversations about current affairs with friends and family, learning of political facts through soft news (Baum, 2003), or accidental exposure to news from the media. The last pattern was first identified with respect to broadcast television and termed "passive learning" (Krugman and Hartley, 1970). Because catch-all television programming mixed news and entertainment, individuals in a low-choice environment tended to watch television in a habitual, often purposeless fashion, and thus had many opportunities to encounter political news, and learn about them, even if they were not actively seeking them. Prior (2007) argued that the advent of cable television in the United States led to the demise of these mechanisms and claimed that the internet, as a high-choice medium, is subject to similar dynamics. However, Tewksbury et al. (2001) proved that the internet can also lead its users to accidental exposure to information. They demonstrated that substantial percentages of the American public in 1996 and 1998 claimed to encounter news about public affairs on the internet as they were online for purposes other than to get the news. While such accidental exposure was predicted by time spent on the web and purposeful exposure to news online, it resulted in increased knowledge about public affairs even after controlling for those factors, suggesting that online incidental exposure to politics could facilitate learning. Thus, whether the internet in and of itself restricts opportunities for 
inadvertent exposure to unwanted content should be considered an empirical question rather than an intrinsic property of the technology, regardless of the fact that on face value it allows greater and broader content choices than previous channels.

Changes in technology and its social uses can contribute to shaping the relationship between use of the internet and political engagement. For one, as access to the internet increased in the US population, studies found stronger correlations between internet use and participation over time (Boulianne, 2009). Bimber and Copeland (2013), while cautioning against grand generalizations about the contextually-determined relationship between internet use and political participation, found that at least one behaviour-attempting to persuade others to vote for a party or candidate-was increasingly correlated with internet use for political information in the US between 1996 and 2008. They suggest that scholars should "conceptualize digital media not as a steady, continuous, or uniform influence on behavior [...] but in terms of changed context for political communication and information" (Bimber and Copeland, 2013: 136). What kind of context, then, do technological innovations provide in terms of the possibility that citizens are inadvertently exposed to political content they were not necessarily seeking? Tewksbury et al. (2001: 546) suggest that the late-1990s emergence of web portals-where news headlines are mixed with entertainment stories and online services such as email and search-explains their finding that accidental exposure was negatively related with political knowledge in 1996 (when portals 
were in their infancy and most internet users generally browsed stand-alone, content-specific individuals websites), but positively correlated to it in 1998 (when portals bridging different genres had become commonplace). Thus, the multiple, complex, and evolving affordances of the internet can accommodate platforms, tools, and uses that can be more or less conducive to accidental exposure to political news at different points in time.

\subsection{Social media, "information exuberance", and accidental exposure}

If the advent of web portals in the late 1990s marked a momentous change in how individuals used the internet and experienced information therein, social media represent an even greater turning point. Social networking sites such as Facebook and Twitter facilitate low-threshold endeavours by individuals-such as posting a comment or sharing a news story—in informal but public or semi-public environments-“third spaces", in Wright's (2012) formulation—closely tied to users' everyday lives. As argued by Chadwick (2009: 30), “Politics in Facebook goes to where people are," as political content travels across individuals' newsfeeds side by side with entertainment updates, lifestyle news, and personal information about friends and acquaintances. The political relevance of this "information exuberance" (Chadwick, 2009) is enhanced by the constant presence of social media in people's everyday lives-considering the countries included in this study, Germans spend 1.4 hours per day on social networking sites, Italians 2.5 hours, and British citizens 1.9 hours ${ }^{1}$ - and by the fact that they bridge public and 
private, political and non-political domains, thus attracting both the politically interested and those who are not inclined to engage with formal politics (Wojcieszak and Mutz 2009).

The importance of these affordances is highlighted by the fact that, as various scholars have demonstrated, social media use can have positive implications for political participation. For example, studying whether the use of Facebook could generate social capital and promote political participation among US undergraduate students in the eve of the 2008 presidential primary, Bode (2012) found that the intensity of engagement with one's online community was associated with political participation online and offline. Similarly, Bode et al. (2014) surveyed a national panel of US adolescents in 2008 and found that blog use, online expression and political use of social media were strong and positive predictors of political participation. Gil de Zúñiga et al. (2014) showed that the use of social networking platforms for social interaction enhances political selfexpression, which in turn increases political activity. Vaccari et al. (2015) surveyed Italians who discussed the 2013 election on Twitter and demonstrated that the more they acquired political information via social media and expressed themselves politically on these platforms, the more they were also likely to be involved in more demanding online political activities such as actively campaigning for a party or candidate.

That social media can be avenues for inadvertent exposure to political content, and that such exposure can in turn be relevant for political engagement, 
has not only been argued theoretically, but also established empirically by some studies. First, Gil de Zúñiga and Valenzuela (2011) found that social media facilitate exposure to diverse political information via weak ties, which can be a first step towards political activity among the uninvolved. Secondly, as individuals encounter messages on social media from other users that they (at least to some extent) know and trust, they are likely to process them in a different way compared with information obtained from impersonal sources such as the mass media. As shown by Messing and Westwood (2014), social media users who receive counter-attitudinal information that is socially endorsed by other users are willing, to an extent, to set their political preferences aside when interpreting it. If social cues can trump individuals' ideological leanings, they can also be expected to trump their cost-benefit calculations in the processing of political information they are not primarily interested in. Bond et al.'s research (2012) provides a highly illustrative example of this diffusion dynamic. In an experiment on Facebook users on the day of the 2010 US midterm elections, they found that exposure to posts indicating that friends and acquaintances had voted resulted in small but statistically significant positive effects on turnout. This implies that the socially cued information conveyed by the experimental treatment found its way into Facebook users' awareness through their news feeds even if they had not actively sought electoral information, and for some the effect was strong enough to motivate them to vote. A more recent anecdotal example of how political messages can travel via social media to reach uninterested audiences was highlighted during 
the 2014 campaign for the Scottish independence referendum. According to news reports, focus groups of undecided voters found "irritation at how social media had been polluted with propaganda", with "I want my Facebook back" a common refrain expressing this sentiment. ${ }^{2}$ This example suggests that-under certain circumstances-social media, rather than acting as watertight "echo chambers" (Sunstein, 2009) that protect individuals from unwanted content, can expose users to political messages that they are not seeking.

In spite of the potential pervasiveness and political relevance of accidental exposure to news on social media, very few studies have taken stock of this phenomenon, and only Kim et al. (2013) have addressed its implications for political participation. Based on a representative sample of the US population, they found positive and significant correlations between accidental exposure to news on various internet platforms (including social media) and both offline and online political participation. They also found that the relationship between online participation and accidental exposure is moderated by relative consumption of entertainment versus news online, so that online participation increased among news-oriented respondents accidentally encountering political information on the web more than among entertainment-oriented respondents inadvertently coming across such news. They thus conclude that "incidental news exposure may [...] broaden gaps in participatory activities between [...] people who use the Internet mostly for entertainment as opposed to people who prefer news." (Kim et al., 2013: 2612) Their findings echo Prior's (2007) in reaffirming the centrality of the 
divide between citizens who are more oriented towards news and those who prefer entertainment. The idea that social media contribute to amplifying inequalities in political knowledge is also supported by Yoo and Gil de Zúñiga (2014), who found that Facebook and Twitter use widens political information gaps between people of different socioeconomic statuses.

\subsection{Accidental exposure to politics on social media: Persisting puzzles}

A number of questions, however, still remain unanswered. First, Kim et al.'s (2013) study is the only one that we could find that addresses the implications of accidental exposure to online information for political engagement, and its conclusions, while consistent with previous studies focusing on different independent variables, should be probed through replication before being deemed as definitive. Secondly, as is unfortunately customary in the literature on digital media and politics, the very few relevant studies have all been conducted in the United States alone (Tewksbury et al., 2001; Kim et al., 2013). As a result, we do not know whether particular features of the US political, social, or media systems affect these relationships, and we cannot generalize the findings from these studies to other countries, even relatively similar Western democracies. This problem is made worse by the fact that the peculiar, often exceptional features of the US make it more of a deviant than a normal case when it comes to digital politics (Vaccari, 2013). Thirdly, Kim et al. (2013) measured accidental exposure to information as an aggregate index of such exposure via eight different online outlets. ${ }^{3}$ Although the index included social media, it confounded them with seven other digital 
platforms, thus failing to capture social networking websites' specific contribution to these patterns. However, as we have seen, there are rather solid theoretical considerations that lead us to expect that social media should differ from other internet tools and environments when it comes to accidentally exposing individuals to political information. Fourthly, although individuals' preferences ${ }^{4}$ for news versus entertainment have surely emerged as an important causal factor shaping citizens' information and participation in the wake of Prior's (2007) research, the role of fundamental political attitudes such as interest in politics should not be overlooked, as it time and again has been found to constitute one of the key motivational drivers of political participation (e.g. Verba et al., 1995) based on robust theoretical reasons (Downs, 1957). Because Kim et al.'s (2013) models do not control for interest in politics, we do not know whether the moderation effects that they found would have persisted once this important variable had been taken into account, nor do we know whether and how interest in politics itself moderates the relationship between accidental exposure and political engagement.

\section{Hypothesis and Research Questions}

In light of these considerations, we aim to shed light on the relationship between accidental exposure to political information via social media and web-based political engagement in comparative perspective. We start from the premise that individuals who are exposed inadvertently to political information on social media can acquire relevant information —as established by Tewksbury et al., 2001—and 
this, in turn, may lead to further engagement in political activities online-as found by Kim et al., 2013. Therefore, our first hypothesis is that:

H1: There is a positive correlation between accidental exposure to political information on social media and political participation online.

Our second goal is to investigate whether and how interest in politics moderates the relationship between accidental exposure and engagement, as found by Xenos and Moy (2007) in studying the relationship between general exposure to online political information (without distinguishing between voluntary and accidental) and participation. Assuming that a relationship exists, the empirical evidence on its direction has been inconclusive. On the one hand, Prior (2007) and Xenos and Moy (2007) suggest that the relationship should be positive, resulting in wider participatory gaps. However, those studies focused on generic internet use and acquisition of political information online rather than accidental exposure to it via social media. Instead, Kim et al. (2013) focused on accidental exposure online, but not specifically on social media, and looked at news versus entertainment preferences as moderating factors, again finding evidence of increased participatory gaps. By contrast, Tewksbury et al. (2001) highlight that web-based accidental exposure can bridge information inequalities-which may have implications on participation (see Shah et al., 2005) —and the theoretical considerations outlined above on the distinctive features and uses of social media also support such expectation, suggesting that the moderating relationship should be negative. In light of these competing considerations, we cannot establish a firm 
hypothesis as to whether interest in politics should be a positive or negative moderator of the relationship between accidental exposure and political engagement. Instead, we formulate the following research question:

RQ1: Does interest in politics positively or negatively moderate the relationship between accidental exposure and online political participation? Finally, we address the lack of comparative research on accidental exposure and political engagement by studying three important Western democraciesGermany, Italy, and the United Kingdom—-that went simultaneously to the polls in May 2014 during the European Parliament elections. Germany, Italy, and the UK all pertain to the realm of established Western democracies, and can thus be meaningfully compared on this basis. They also differ from one another in many relevant ways-including the diffusion of social media (which are used by $57 \%$ of British citizens, $42 \%$ of Italians, and $35 \%$ of Germans $)^{5}$ and citizen participation in the 2014 European election (where turnout was 57\% in Italy, 48\% in Germany, and $32 \%$ in the UK). ${ }^{6}$ Given the lack of comparative studies-and theories-on these topics, we could not derive specific, theoretically grounded expectations on whether and how systemic differences across these countries may shape the relationship between accidental exposure and political engagement, and we are thus mainly guided by an explorative interest. Comparing three different countries will allow us, first, to identify country-level effects, and, secondly, to assess the robustness of our findings across different political systems. Hence, we investigate the following research question: 
RQ2: Are there significant differences across Germany, Italy, and the United Kingdom in the strength and direction of the correlation between accidental exposure to political information on social media and political participation online?

\section{Data, Variables, and Models}

\subsection{Data}

Data presented in this manuscript have been collected through three CAWI (Computer Assisted Web Interviewing) surveys conducted in Germany, Italy, and the United Kingdom in the aftermath of the European Election held on 22-25 May 2014. Surveys were administered by IPSOS Italia and were in the field between May 28-June 20 in Germany, May 27-June 20 in Italy, and May 29-June 20 in the United Kingdom.

For each country, a representative sample $(N=1,750)$ of internet users aged 16-74 was constructed based on the following variables: age, gender, region of residence (based on NUTS $2^{7}$ classification), occupational condition, and educational level. These samples were built within online panels administered by IPSOS and respondents were offered non-monetary incentives to take part in the surveys. Invitations were sent in each country until we achieved a sample that both reached our numeric target of 1,750 and was representative of the target population across the required variables. To obtain these goals, 10,517 invitations were sent in Germany, 8,514 in Italy, and 9,008 in the UK. ${ }^{8}$ Response rates based 
on AAPOR's RR1 standard (2011) are thus 17\% for Germany, 21.4\% for Italy, and $20.1 \%$ for the United Kingdom. Because the quota sampling allowed us to achieve a very close fit between key characteristics of the population and the sample, no weighting was required for the German and Italian samples. On the contrary, since the percentage of unemployed respondents in the British sample was higher than in national figures, we weighted ${ }^{9}$ the British data to ensure that sample margins matched population margins with respect to working conditions.

\subsection{Variables and Models}

Our hypotheses and research questions focus on the relationships between political participation online and accidental exposure to political information on social media, interest in politics, and country of residence.

Our dependent variable measures levels of political engagement online. In order to capture a broad realm of online political actions, we developed an index aggregating questions from a battery containing six items related to internet-based political endeavours. All items were introduced by the following question: "Various political activities are carried out via the Internet. During the past 12 months have you...?" (Response modes were: "Yes”, “No”, and “Don't Remember”). We coded "Yes" as 1, "No" as 0, and treated "Don't remember" as missing values. The index aggregates the number of "Yes" answers to the following items: "sent an email to a political leader or party" (undertaken by $10.2 \%$ of German, $15.9 \%$ of Italian, and $17.9 \%$ of British respondents); "signed an online petition" (29.2\% German, $31.4 \%$ 
Italian, 40.5\% British); “discussed national politics on a forum or blog" $(14.2 \%$ German, 19.2\% Italian, 21.1\% British); "tried to convince someone to vote for a specific candidate/party/leader using email” (6\% German, 12.5\% Italian, 13.4\% British); "used the Internet to involve other people in online and offline political activities" (9.2\% German, 14\% Italian, 13\% British); and "participated in an offline political activity to which you were invited via the Internet" (8.3\% German, $16.5 \%$ Italian, $12.3 \%$ British). The index thus ranges from 0 to 6 , and averages .76 $(\mathrm{SD}=1.32)$ in Germany, $1.08(\mathrm{SD}=1.64)$ in Italy, and $1.15(\mathrm{SD}=1.57)$ in the UK. Cronbach's $\alpha$ for the index was .770 for the German, .817 for the Italian, and .776 for the British sample.

The independent variables required to test our hypothesis and answer our research questions involve accidental exposure to political information on social media (H1), interest in politics (RQ1), and country of residence (RQ2). Following Tewksbury et al. (2001), we test H1 through the following survey question: "When you use social networks / social media platforms (e.g. Facebook, Twitter, YouTube, etc.), how often do you come across news and information on current events, public issues, or politics when you may have been going online for a purpose other than to get the news?". Response modes were: "Always or very often" $2.9 \%$ of German, 6.8\% of Italian, and 6\% of British respondents); “Often” (13.7\% German, 26.2\% Italian, 21.7\% British); “Sometimes” (40.7\% German, 47.4\% Italian, 42.4\% British); "Never" (42.7\% German, 19.6\% Italian, 29.9\% British); and “I don’t know" (treated as missing values) ${ }^{10}$. The frequencies of this variable are already 
indicative of the fact that social media facilitate accidental exposure at least occasionally among a vast portion of the population, and for between one-third (in Italy) and one-seventh (in Germany) of our samples this happens frequently.

To answer RQ1 we consider the interaction term between the variable measuring accidental exposure and a variable measuring interest in politics, after centring both around their means ${ }^{11}$ in order to mitigate risks of distortion due to multicollinearity. Interest in politics is measured by the following question: "In general, how interested are you in politics?". Response modes were: "Not at all interested" (6.4\% of German, $8.8 \%$ of Italian, and 9.6\% of British respondents); "Slightly interested" (31.4\% German, 32.2\% Italian, 24.8\% British); "Moderately interested" (39\% German, 41.6\% Italian, 34.5\% British); "Very interested" (23.1\% German, 17.4\% Italian, 31.3\% British); and "I don't know" (treated as missing values).

We conducted our analyses on a pooled dataset to better assess the significance of differences in the strength of the relationships between variables in the three countries (Gelman and Hill, 2007). We created country dummy variables to cluster respondents around the countries where they reside, considering Germany as the reference category. To answer RQ2 we include the interaction terms between the dummy variables indicating the national sub-samples and accidental exposure to political information, again taking Germany as the reference category. 
Since our dependent variable is a count variable, we employ Poisson regression, which is best suited to analyse these types of data. We ran three separate regressions (incrementally including the interaction terms we considered) controlling for gender, age, education, income, ideology, political efficacy, ${ }^{12}$ and trust in political parties. Moreover, since Tewksbury et al. (2001: 542) showed that "those who tend to look for news online are the ones who tend to come across it by accident as well", we also control for exposure to political news on different media channels, including websites and social media. All nondichotomous independent and control variables have been normalized to range between 0 and 1 to facilitate comparisons among coefficients.

\section{Findings}

Table 1 presents three Poisson regression models that predict respondents' online political engagement as a function of country of residence, socio-demographic characteristics, political attitudes, sources of news, and accidental exposure to political information on social media. Model 0 does not include any interaction while in Models 1 and 2 we added the interactions of accidental exposure with interest in politics (Model 1) and with country of residence (Model 2).

\section{TABLE 1 ABOUT HERE}

Our first hypothesis suggests a positive correlation between the frequency with which individuals are accidentally exposed to political information on social media and the number of political activities that they conduct online. As can be observed 
from Table 1, H1 is confirmed by the data: the coefficient expressing the correlation between accidental exposure to political information on social media and political participation online remains positive and significant in all three models. This means that, holding all other variables equal, the more frequently individuals report that they inadvertently encounter political information on social media, the more they also engage with different political activities online.

Our first research question investigates whether and in which direction interest in politics moderates the relationship between accidental exposure to politics on social media and political participation online. The answer lies in Model 1, where the coefficient for the interaction term between accidental exposure and interest in politics is significant and negative. Thus, interest in politics-which in itself is correlated positively and significantly with online political engagementnegatively moderates the relationship between incidental encounters with political information on social media and online political participation. All else being equal, the strength of the correlation between accidental exposure to political information on social media and online political participation decreases as interest in politics increases.

As can be seen by comparing the pseudo- $\mathrm{R}^{2}$ coefficients in Models 0 and 1 , adding the interaction term does not increase the model's overall goodness of fit. However, effect size statistics suggest that the interaction between accidental exposure and interest in politics has substantial implications for respondents' online participation. As an example, setting all variables to their mode or median 
value, for a hypothetical British ideologically centrist respondent who is highly interested in politics (a standard deviation above the mean) a shift between low (a SD below the mean) and high (a SD above the mean) accidental exposure to politics on social media results in an increase in the value of the online political participation index from .88 to 1.50 (the same variable increases from .83 to 1.43 for an Italian and from .62 to 1.06 for a German comparable respondent). For an identical British respondent who is scarcely interested in politics (a SD below the mean) the same shift in frequency of accidental exposure to politics on social media results in an increase in the value of the online political participation index from .41 to .88 (from .39 to .84 for an Italian and from .29 to .62 for a German respondent). This means that, while respondents highly interested in politics receive $\mathrm{a}+71 \%$ boost in their online political activity by a substantial increase in their incidental encounters with political content on social media, respondents scarcely interested in politics receive a $+113 \%$ boost by a similar experience.

Finally, our second research question focuses on differences across Germany, Italy, and the United Kingdom in the strength and nature of the relationship between accidental exposure to political information on social media and political participation online. Model 2 answers this question by taking Germany as reference category (see again Table 1). The coefficients for the interaction terms between countries (Italy and United Kingdom) and accidental exposure to political information are negative and significant. The answer to RQ2 is thus that, all else being equal, the relationship between frequency of 
inadvertently encountering political information on social media and political engagement online is weaker among both British and Italian respondents than among German ones. This finding should be considered in light of the fact that in all three models the coefficients for the variables clustering the British and Italian sub-samples are positive and significant. Thus, after controlling for sociodemographic characteristics, political attitudes, and media use, British and Italian respondents are involved in more online political activities than German ones when they do not get accidentally exposed to political content on social media. But, when they do come across political information on web 2.0 platforms that they were not necessarily seeking, British and Italian respondents experience a smaller engagement boost than German ones-as could already be inferred by the effect sizes comparisons presented above.

\section{Discussion}

We have shown that, contrary to earlier predictions, inadvertent encounters with politics on social media are likely to reduce the online engagement gap between citizens with high and low interest in politics. This was especially the case among German respondents (who were on average less engaged in online political activities) than among Italian and British ones (who were more engaged).

These findings challenge the widespread notion that the web represents a milieu where, when it comes to political information and engagement, the "rich get richer" while the rest of the electorate is not affected. Such vision was developed in 
the early days of digital politics and based on the assumption that the web was solely capable of enhancing patterns of selective exposure to politics. By contrast, in the contemporary online environment, accidental exposure to political content can hardly be considered an exceptional event affecting marginal segments of users - as witnessed by the fact that in our sample $16.6 \%$ of German, $33 \%$ of Italian, and $27.7 \%$ of British respondents claimed to frequently encounter political information on social media even if they do not necessarily seek it.

Before addressing the implications of our findings, it is important to recognize some limitations of the present study, from which we suggest directions for future research. First, the cross-sectional nature of our survey data does not allow us to identify with certainty the direction of the causal patterns underlying the correlations that we found. More robust causal claims would be warranted by longitudinal or experimental rather than cross-sectional survey data and more work is needed to disentangle the causal mechanisms behind the correlations presented here. For instance, what specific properties of the political information incidentally encountered on social media mobilize people who are not highly interested in politics? Is it the sheer fact of getting information-although unsearched-that motivates them to engage with politics? Or is it the specific content of such information-e.g. the fact that it supports or challenges their political beliefs-or its source-e.g. that it comes from someone who is trusted or liked-that mobilizes people who are scarcely interested in politics? 
Another limitation of this research involves its reliance on self-reported measures of online political involvement as well as both purposeful and accidental exposure to political information. While all self-reports are problematic-and the latter one we employed is particularly so since it depends on respondents' subjective assessments of their purposes on social media and fickle memories of their multiple interactions therein-it would be very difficult to measure these phenomena in any other way. However, experiments may help assess the effects of manipulations that involve different degrees of distance between the message and the subjects' purposes, preferences, and interests.

Our study is also limited due to the nature of our sample, which is based on an online administered panel. Although this panel is fully representative of the population with internet access in terms of its main socio-demographic characteristics, its respondents, having accepted to participate in a CAWI panel, may still have different characteristics than the population they should represent in terms of the ways in which they use the internet and social media. Therefore, it would be important to replicate our analyses on random samples of the whole national populations of the countries we studied. At the same time it should be noted that even in such surveys, the questions on which our research is based can only be asked to internet users.

Finally, even if our comparative approach has begun to address our lack of knowledge on how systemic features affect the relationship between social media and political engagement, ours has been a first attempt that should be further 
developed in the future. We have no a priori reason to expect that the patterns we have identified here should vary substantially in different political contexts because the main social media platforms operate in similar ways across Western democracies. However, we reached opposite conclusions to Kim et al. (2013), who tested different models in studying an American sample. We cannot tell whether these differences have to do with dissimilarities between our respective research designs or between the countries we studied. A promising line of research in this direction is to probe whether the extent to which web 2.0 environments accidentally expose individuals to political information varies as a function of differences in national media systems-which have been shown to impact citizens' levels of, and inequalities in, political information (Curran et al., 2009) and participation (van Kempen, 2007). Studies comparing how broadcast and social media specifically contribute to citizens' unintended encounters with political information may help clarify this issue.

\section{Conclusion}

Accidental encounters with political content on social media can result in a reduction in the online engagement gap between citizens with high and low interest in politics, motivating those who are less interested to actively partake in politics online, and especially so in contexts where web-based participation is relatively less common. Four important implications derive from these findings. 
First, encountering political information online-even when not deliberately seeking it—can substitute pre-existing interest in politics in motivating citizens to participate in politics. Social media are thus a context where something new can happen to political participation-or where something can happen to new people-instead of just a new context where the "usual suspects" are active.

Secondly, political actors can try to harness these affordances of social media to reach citizens who are not highly interested in politics by indirectly "invading" their social media timelines via the "exuberance" of other users. This was indeed one of the cornerstones of the digital strategy of the Obama 2012 campaign (Bimber, 2014). By sharing political information on their social media profiles, engaged citizens increase the likelihood that less interested citizens get accidentally exposed to political content—provided that activists manage to reach non-activists in these environments. Due to the dynamics described in this manuscript, newcomers can thus be mobilized into political participation, thus renewing the activists' base (see Vaccari and Valeriani, 2013).

Thirdly, the fact that accidental exposure levels the gap in political participation between citizens who are already highly interested in politics and those who are not could have positive implications for democracy. Citizens' disengagement from politics due to lack of interest is a widespread phenomenon, as also emerged in our survey where $40 \%$ of Italian, $37.8 \%$ of German, and $34.4 \%$ of British respondents declared to be "not at all" or only "slightly" interested in 
politics. Accidental exposure to political information on social media can reinvigorate political processes by augmenting engagement especially among uninterested citizens.

Fourthly, there are multiple pathways that link social media and political engagement, and not all of them depend on users' exercising technology-enabled, conscious choices as to the kinds of messages and sources they interact with. Digital and social media are multifaceted contexts where different purposes and uses—such as keeping in touch with friends and reading political news-interact and overlap in often unexpected ways that are not captured by one-size-fits-all explanations premised on static views of technological affordances. 


\section{References}

The American Association for Public Opinion Research (2011) Standard Definitions: Final Dispositions of Case Codes and Outcome Rates for Surveys. 7th edition. AAPOR.

Baum MA (2003) Soft news and political knowledge: Evidence of absence or absence of evidence?. Political Communication, 20(2): 173-190.

Bimber BA (2003) Information and American democracy: Technology in the evolution of political power. New York: Cambridge University Press.

Bimber BA (2014) Digital media in the Obama Campaigns of 2008 and 2012: Adaptation to the personalized political communication environment. Journal of Information Technology \& Politics, 11(2): 130-150.

Bimber BA and Copeland L (2013) Digital media and traditional political participation over time in the US. Journal of Information Technology \& Politics 10(2): 125-137.

Bimber BA and Davis R (2003) Campaigning online: The Internet in US elections. New York: Oxford University Press.

Bode L (2012) Facebooking it to the polls: a study in online social networking and political behavior. Journal of Information Technology \& Politics 9(4): 352-369.

Bode L, Vraga EK, Borah P and Shah DV (2014) A new space for political behavior: Political social networking and its democratic consequences. Journal of Computer-Mediated Communication 19(3): 414-429. 
Bond RM, Fariss CJ, Jones JJ, Kramer AD, Marlow C, Settle JE and Fowler JH (2012) A 61-million-person experiment in social influence and political mobilization. Nature 489(7415): 295-298.

Boulianne, S. (2009). Does Internet use affect engagement? A meta-analysis of research. political communication, 26(2), 193-211.

Brundidge J and Rice RE (2009) Political engagement online: Do the information rich get richer and the like-minded more similar? In: Chadwick A and Howard PN (eds) Routledge handbook of Internet politics. New York: Routledge, pp. 144-156.

Chadwick A (2009) Web 2.0: New Challenges for the Study of E-Democracy in an Era of Informational Exuberance. I/S: A Journal of Law and Policy for the Information Society 5(1): 9-41.

Curran, J, Iyengar S, Lund AB and Salovaara-Moring I (2009) Media System, Public Knowledge and Democracy A Comparative Study. European Journal of Communication 24(1), 5-26.

Downs A (1957) An Economic Theory of Democracy. New York: Harper.

Gelman A and Hill J (2007) Data Analysis Using Regression and Multilevel/Hierarchical Models. New York: Cambridge University Press.

Gil de Zúñiga H and Valenzuela S (2011) The mediating path to a stronger citizenship: Online and offline networks, weak ties, and civic engagement. communication research 38(3): 397-421. 
Gil de Zúñiga H, Molyneux L, and Zheng P (2014) Social media, political expression, and political participation: Panel analysis of lagged and concurrent relationships. Journal of Communication 64(4): 612-634.

Eveland Jr WP and Scheufele DA (2000) Connecting news media use with gaps in knowledge and participation. Political Communication 17(3): 215-237.

Junco R (2013) Comparing actual and self-reported measures of Facebook use. Computers in Human Behavior 29(3): 626-631.

Kim Y, Chen HT, and Gil de Zúñiga H (2013) Stumbling upon news on the Internet: Effects of incidental news exposure and relative entertainment use on political engagement. Computers in Human Behavior 29(6): 2607-2614.

Krugman HE and Hartley EL (1970) Passive learning from television. Public Opinion Quarterly 34(2): 184-190.

Margolis M and Resnick D (2000) Politics as Usual: The Cyberspace Revolution. Thousand Oaks: Sage Publications.

Messing S and Westwood SJ (2014) Selective Exposure in the Age of Social Media: Endorsements Trump Partisan Source Affiliation When Selecting News Online. Communication Research 41(8): 1042-1063.

Norris P (2003) Preaching to the converted? Pluralism, participation and party websites. Party Politics 9(1): 21-45.

Prior M (2007) Post-broadcast democracy: How media choice increases inequality in political involvement and polarizes elections. Cambridge: Cambridge University Press. 
Scheufele DA and Nisbet MC (2002) Being a Citizen Online New Opportunities and Dead Ends. The Harvard International Journal of Press/Politics 7(3): 55-75.

Shah, D. V., Cho, J., Eveland, W. P., \& Kwak, N. (2005). Information and expression in a digital age modeling Internet effects on civic participation. communication research, 32(5), 531-565. doi: 10.1177/0093650205279209

Sunstein CR (2009) Republic. com 2.0. Princeton: Princeton University Press.

Tewksbury D, Weaver AJ and Maddex BD (2001) Accidentally informed: Incidental news exposure on the World Wide Web. Journalism \& Mass Communication Quarterly 78(3): 533-554.

Vaccari C (2013) Digital politics in Western democracies: a comparative study. Baltimore: Johns Hopkins University Press.

Vaccari C and Valeriani A (2013) Follow the leader! Direct and indirect flows of political communication during the 2013 general election campaign. New Media \& Society, 1461444813511038.

Vaccari C, Valeriani A, Barberá P, Bonneau R, Jost JT, Nagler J, and Tucker JA (2015) Political Expression and Action on Social Media: Exploring the Relationship Between Lower-and Higher-Threshold Political Activities Among Twitter Users in Italy. Journal of Computer-Mediated Communication 20(2): 221-239, doi: $10.1111 /$ jcc4.12108.

Van Kempen H (2007) Media-party parallelism and its effects: A cross-national comparative study. Political Communication 24(3): 303-320. 
Verba S, Schlozman KL and Brady HE (1995) Voice and equality: Civic voluntarism in American politics. Cambridge, MA: Harvard University Press.

Wojcieszak M, Mutz D (2009) Online Groups and Political Discourse: Do Online Discussion Spaces Facilitate Exposure to Political Disagreement? Journal of Communication 59(1): 40-56.

Wright S (2012) Politics as usual? Revolution, normalization and a new agenda for online deliberation. New Media \& Society 14(2): 244-261.

Xenos M and Moy P (2007) Direct and differential effects of the Internet on political and civic engagement. Journal of Communication 57(4): 704-718.

Yoo SW and Gil de Zúñiga H (2014) Connecting blog, Twitter and Facebook use with gaps in knowledge and participation. Communication \& Society 27(4): 33-48. 
Table 1 - Estimated coefficients for engagement in online political activities

\begin{tabular}{|c|c|c|c|c|c|c|}
\hline & \multicolumn{2}{|c|}{ Model 0} & \multicolumn{2}{|c|}{ Model 1} & \multicolumn{2}{|c|}{ Model 2} \\
\hline & Coeff. & s. e. & Coeff. & s. e. & Coeff. & s.e. \\
\hline Accidental exposure & $1.014^{* * *}$ & .079 & $1.143^{* * *}$ & .098 & $1.405^{* * *}$ & .140 \\
\hline Interest in politics & $.972^{* * *}$ & .097 & $1.067^{* * *}$ & .104 & $1.059^{* * *}$ & .105 \\
\hline Interest*accidental exp. & - & - & $-.642 *$ & .262 & $-.637^{*}$ & .264 \\
\hline \multicolumn{7}{|c|}{ Country*accidental exp. (Germany as reference) } \\
\hline Italy*accidental exp. & - & - & - & - & $-.329 *$ & .165 \\
\hline Uk*accidental exp. & - & - & - & - & $-.355^{*}$ & .149 \\
\hline \multicolumn{7}{|c|}{ Country (Germany as reference) } \\
\hline Italy & $.299^{* * *}$ & .055 & $.294^{* * *}$ & .055 & $.338^{* * *}$ & .062 \\
\hline United Kingdom & $.350^{* * *}$ & .050 & $.346^{* * *}$ & .050 & $.393^{* * *}$ & .057 \\
\hline \multicolumn{7}{|c|}{ Ideology (un-aligned as reference) } \\
\hline Right & $.250^{* * *}$ & .063 & $.251^{* * *}$ & .063 & $.250^{* * *}$ & .063 \\
\hline Centre & $.242^{* * *}$ & .070 & $.244^{* * *}$ & .069 & $.244^{* * *}$ & .069 \\
\hline Left & $.233^{* * *}$ & .060 & $.232^{* * *}$ & .060 & $.235^{* * *}$ & .060 \\
\hline Trust in political parties & -.025 & .063 & -.019 & .063 & -.017 & .064 \\
\hline Political efficacy & $.369^{* * *}$ & .098 & $.351^{* * *}$ & .098 & $.348^{* * *}$ & .098 \\
\hline \multicolumn{7}{|c|}{ Sources of political information } \\
\hline Social Media & $.551^{* * *}$ & .091 & $.555^{* * *}$ & .090 & $.538^{* * *}$ & .090 \\
\hline Internet & $.330^{* *}$ & .114 & $.314^{* *}$ & .114 & $.314^{* *}$ & .113 \\
\hline Newspapers & $.485^{* * *}$ & .082 & $.484^{* * *}$ & .082 & $.488^{* * *}$ & .082 \\
\hline Radio & $.355^{* * *}$ & .076 & $.354^{* * *}$ & .076 & $.361^{* * *}$ & .076 \\
\hline Television & $-.416^{* * *}$ & .095 & $-.430 * * *$ & .094 & $-.422^{* * *}$ & .095 \\
\hline Gender (Male) & .017 & .039 & .019 & .039 & .020 & .0385 \\
\hline Age & -.007 & .086 & -.013 & .086 & -.016 & .0858 \\
\hline Education & .090 & .059 & .094 & .059 & .095 & .0593 \\
\hline Income & $-.140^{*}$ & .069 & -.135 & $.068^{*}$ & $-.135^{*}$ & .0687 \\
\hline Constant & $-2.305^{* * *}$ & .100 & $-1.379^{* * *}$ & .102 & $-1.409^{* * *}$ & .1044 \\
\hline Likelihood ratio $\chi^{2}$ & $2573.000^{* * *}$ & & $2582.966^{* * *}$ & & $2590.950^{* * *}$ & \\
\hline Pseudo-R ${ }^{2}$ & .375 & & .375 & & .376 & \\
\hline$N$ & 3683 & & 3683 & & 3683 & \\
\hline
\end{tabular}

Note: Variables expressing accidental exposure to political information on social media and interest in politics are centred around their means in Models 1 and $2 .{ }^{* * *} \mathrm{p} \leq .001{ }^{* *} \mathrm{p} \leq .01{ }^{*} \mathrm{p} \leq .05$ 


\section{Endnotes}

${ }^{1}$ See http://wearesocial.net/blog/2014/01/social-digital-mobile-worldwide2014/ (accessed 30 December 2014). It should be noted that, as demonstrated by Junco (2013), survey respondents tend to overreport the time they spend on social networking websites. Since the figures cited here are based on survey data, they might be affected by such limitation.

${ }^{2}$ See http://www.theguardian.com/commentisfree/2014/dec/23/year-crisisdigital-revolution-uk-politics-2014 (accessed 30 December 2014).

${ }^{3}$ These are: search engines, headlines on a portal, e-mail, forums or listservs, blogs, social networking sites, advertisements, and instant messaging (Kim et al. 2013: 2610).

${ }^{4}$ Whereas Prior (2007) employs survey questions that measure respondents' preferences for news versus entertainment content, Kim et al. (2013: 2610) employ questions that measure respondents' exposure to these types of content online. Although Kim and colleagues are very transparent about their choice, the questions they employed measure a slightly different concept to Prior's instruments and thus only partially enable to test Prior's theory. ${ }^{5}$ See http://wearesocial.net/blog/2014/01/social-digital-mobile-worldwide2014/ (accessed 30 December 2014). The percentages are based on the total population of each country, including individuals without internet access. ${ }^{6}$ See http://www.europarl.europa.eu/elections2014-results/en/turnout.html (accessed 30 December 2014). 
${ }^{7}$ NUTS stands for "Nomenclature of Territorial Units for Statistics" and is a geographical classification that subdivides territories of the European Union into regions at three different levels. See http://www.ons.gov.uk/ons/guidemethod/geography/beginner-s-guide/eurostat/index.html (accessed 9 January 2015).

8 In Germany, 7,507 recipients did not open the survey link, 1,002 abandoned the interview or were screened out, and 258 turned out to be over quota. In Italy, 6,146 recipients did not open the survey link, 288 abandoned the interview or were screened out, and 330 turned out to be over quota. In the UK, 6,712 recipients did not open the survey link, 243 abandoned the interview or were screened out, and 303 turned out to be over quota.

9 To ensure that weighting did not introduce any bias, we ran our models both with weighted and unweighted data for the British sample. Results were consistent across the two analyses.

10 Percentages have been calculated based on all respondents, excluding those who answered "don't know/don't remember" but including those who claimed not to have social media profiles (who could answer that they "never" accidentally encountered political information therein). Since in our sample 82.1\% of German, $88 \%$ of Italian and $85.9 \%$ of British respondents declared to have at least one online social networking profile, we are confident that cross-country variations we found in our study could not be simply explained by differences in rates of social media usage. 
${ }^{11}$ After recoding and normalizing variables in a range between 0 and 1 , the mean value for accidental exposure is .33 and the mean value for interest in politics is .59 .

12 This variable has been created by recoding and aggregating answers to three different questions all introduced by the phrase: "How much do you agree with these statements?...". The statements were: "People like me have no influence on what the government does"; "Politicians are interested in what people like me think" ; "Sometimes politics is so complicated that you cannot understand what is happening". 